\title{
GEOSYSTEMS TRANSFORMATION IN THE NORTHERN PART OF BAIKAL NATURAL TERRITORY (study and mapping)
}

\author{
Tatyana Konovalova ${ }^{12}$, Alexander Sizykh ${ }^{3 *}$ \\ ${ }^{I}$ V.B. Sochava Institute of Geography, Siberian Branch of Russian Academy of Sciences, Irkutsk, 664033, Russia; \\ ${ }^{2}$ Irkutsk State University, 664033 Irkutsk, 126 Ulan-Batorskay str., Russia; \\ ${ }^{3 *}$ Siberian Institute of Plant Physiology and Biochemistry of RAS SB, 664033 Irkutsk,132 Lermontova str., Russia; \\ "Corresponding Author Alexander Sizykh, e-mail: alexander.sizykh@gmail.com;
}

Received June 2021; Accepted July 2021; Published August 2021;

DOI: https://doi.org/10.31407/ijees11.409

\begin{abstract}
We present the result of the study of geosystems transformation in hard-to-reach northern areas of Baikal Natural Territory. It is stated that geosystems transformation is determined in many aspects by changes in matter and energy links in the geosystems resulting from the effect of Baikal Rift Zone. There are considerable contrasts in geosystems situated at different tectonic sites of the territory, a strong character of their links, the relation to a definite rocks composition, to the areas of past and modern glaciations. We consider basic methods of mapping of geosysems transformations. The mapping supposes solution of three main tasks, which are traditionally determined as identification, systematization and interpretation of the geosystems. They consist of the following steps: determination of diagnostic features of the geosystems; time and space synthesis in the whole taking into account regional and typological specifics, structural-dynamic and evolutional transformations; provision of the possibility to form ideas on the trends of geosystems transformation by names and classification positions. Each typological unit of geosystems has different taxonomic identification and reflects different physical-geographic features of a region and diverse geographic relations resulting from external functional properties of a geographic environment structure coordinating the peculiarities of their transformation on the base of macrogeographic regularities.
\end{abstract}

Key words: geosystem, mapping, transformation mechanisms, landscape boundaries. 